\title{
Study on the Frost Mechanism of Concrete
}

\author{
Xiaoning Su \\ China: University of Science and Technology LiaoNing ; Applied Technical School \\ sxnsxn2008@163.com
}

Keywords: concrete; freeze-thaw damge; anti-freezing mixture

Abstract. This paper concluded and analyzed the depiction that concerned concrete frost mechanism for many years. The main theories are phase change process of water into ice, the existence of water in the concrete forms and gap on the water hydrostatic pressure and osmotic pressure hypothesis, freeze-thaw critical saturated value and moisture migration and dry.

\section{Introduction}

In many regions of China, winter temperatures are below $-5^{\circ} \mathrm{C}$.Low temperature is very bad for concrete, the damage of concrete in those regions is relevant to freeze-thaw action of concrete. Freeze-thaw cycles is related to the service life of the building, engineering quality, safety, etc. Freeze-thaw damage is one of the main form of damage of concrete hydraulic structure, freeze-thaw damage seriously affect the normal operation of the hydraulic structure. We must fully understand the seriousness of it, understand its failure reason, the correct design, construction and management measures to mitigate the effects of freezing and thawing damage to buildings, on the issue at home and abroad research of experts on the concrete frost resistance of concrete is becoming more and more attention, their theory constantly, various methods is constantly, through research on mechanism of concrete seas are trying to find more effective to improve the performance of concrete frost resistance, more economic, more practical method.

\section{Frost Mechanism of Concrete at Home and Abroad Research Situation}

\section{Phase Change Process of Water into Ice}

Hardening of concrete under normal temperature is not the hydration of cement, the cement hydration products, aggregate, water, air, gas - liquid - solid three phase equilibrium system composed of, when the concrete at minus temperature, its internal pore water in the from liquid to solid phase shift will occur.The phenomenon of concrete from damaging people originally just $9 \%$ water expands when it freezes the natural phenomenon to explain, think this kind of phenomenon and the airtight container filled with water after cold burst damage. When the volume of more than $91 \%$ of pore solution, freezing expansion pressure on concrete structure damage. But this simplistic view can't explain complex dynamics process of concrete from damaging. And experiment shows that water saturation is lower than $91 \%$, the concrete can also be from damaging. This means far more than the mechanism of concrete from damaging as simple as that.A lot of research suggests that for many reasons that affect the concrete from damaging, its mechanism is very complex. But in essence, cold damage of concrete mainly depends on the form of the water in the concrete.

\section{The Existence of Water in the Concrete Forms and Gap on the Water}

At the beginning of the concrete hardening concrete water in the form .

Water of crystallization. Such as ettringite crystal contained in the water of crystallization water said, it is impossible to freeze the water.

The adsorption of water. Also known as gel water, existence and all kinds of natural gas hydrates, 
such as gelation of ettringite hole, due to the gel hole size is very small, generally between 15 to $20 \mathrm{~A}$ only one order of magnitude larger than the water molecules, the water under the natural conditions can be thought of as impossible to freeze.

The pore water. Exists in wool stoma, the water can be frozen. By the formula:

$$
\operatorname{RTLn}(\operatorname{Pr} / \mathrm{Po})=\mathrm{M} / \mathrm{d}(2 \sigma / \mathrm{r})
$$

For the gas constant $\mathrm{R}$ type; $\mathrm{T}$ is the absolute temperature; Pr for the curvature radius of capillary tube in the vapor pressure of liquid; Po for bulk liquid vapor pressure; D is the density of water; Sigma as the surface tension; $\mathrm{R}$ for the liquid in the capillary radius of curvature. That with the decrease of the pore radius, the freezing point of water vapor. Such as radius of $5 \mathrm{~A}$ hole in the pure water for freezing $-5{ }^{\circ} \mathrm{C}$, and the radius of $1.5 \mathrm{~A}$ hole water freezes until $-70^{\circ} \mathrm{C}$.

Free water.Also known as free water, exists between all kinds of solid particles, can be frozen water.Thus the concrete freezing injury as a result of free water and large aperture due to the capillary water freeze. Water into ice volume increases about $9 \%$, if the hardened concrete pore free water in the saturated, will create internal stress within the concrete, the concrete structure damage.

A similar statement this statement, concrete is a kind of cement, aggregate thickness and porosity of various heterogeneous composite material, at least a certain size of aperture of wool stoma and concrete mixing mixture wrapped into the big hole in the water of the seas, is the main cause of concrete from damaging. When reduced to $0{ }^{\circ} \mathrm{C}$ temperature below a certain temperature, due to the concrete freezes in the cold of the water in the pores of cement produced inflation pressure, when the inflation pressure is too large and more than the tensile strength of cement stone, it will undermine cement or even damage. To a certain degree of negative temperature concrete under the seas in addition to related to the intensity of the cement itself, also related to concrete porosity, and degree of porosity on the water, especially the pore structure of concrete frost resistance. The pore in general can be divided into cement concrete gel hole, stoma and large pores, such as three, so the gel holes are not affected by cold. Aperture small wool stoma (320 a) below, due to low freezing point of water, is not subject to frost damage is generally not.And more than 1000 a stoma is affected by freeze-thaw action; Big freezes the water in the pores is concrete the main hazard factors from damaging[1]. The same as a theory of this theory, the form of the water in the concrete is determined by the pore structure of concrete, concrete in the pore water and free water also means that exist in the large water in the pores. The concrete level of freezing injury associated with the degree of porosity on the water is definitely the phase change process of water into ice.

\section{Hydrostatic Pressure and Osmotic Pressure Hypothesis}

Hydrostatic pressure theory: concrete under wet condition, the first wool stoma with water absorption, concrete mixing forming during take some big air bubble, the air bubble wall also can absorb water, but under atmospheric pressure is hard to suck full water, total also can leave without water space. Under the low temperature water ice in wool stoma, and volume expansion, tends to push not frozen water to the big air bubble flow direction, that is a hydrostatic pressure.

Osmotic pressure: it is by the hole in the ice and frozen water caused by the difference between the free energy of the two phases. The saturated vapor pressure of ice is less than water. The vapor pressure difference driving not frozen water to the frozen area migration, that is the osmotic pressure. Freeze-thaw cycles on the damage concrete is caused by the volume expansion of water into ice hydrostatic pressure and water vapor pressure difference caused by the osmotic pressure is the result of joint action.[2][ for both what was the main reason for the freezing, many scholars have different profile. Tianyuan Li of hunan university, and starting from the theoretical analysis and calculation of the experimental phenomena of objective existence to demonstrate hydrostatic pressure and osmotic pressure size, harm and degree of role. Finally it is concluded that hydrostatic pressure is the main factor that concrete frost damage to.[3] 
This theory is in the affirmation of the pore structure of concrete and concrete water form, on the basis of further deepening the research on the mechanism of concrete seas, and the mechanics and mathematics application, makes the understanding of the mechanism of cold more scientific about concrete.

\section{Freeze-thaw Critical Saturated Value}

Swiss Fagerland has proposed "critical full water freezing and thawing method". This method the basic idea that can be frozen water content of concrete can accommodate exists a critical value, when the internal water have not reached the critical value, even in cold environment, in concrete will not freezing, reaches the critical value, the concrete will quickly destroy.[4][

According to power for many years of experiments and theory study, freeze-thaw damage of concrete's biggest factor is the freezing temperature, cooling speed and full water level (or saturation), especially in the full extent of water influence for the most.

Water is the main reason of the concrete cold damage, the existing concrete with antifreeze requirements should be to limit the water cement ratio, water cement ratio, the smaller the frost resistance, the better. If the pore water in concrete are not reach saturation, and there is no frost heaving damage and moisture migration, thus "freeze-thaw critical saturated value method", is added based on the above theory.

\section{Moisture Migration and Dry}

Back in the '50 s and' $60 \mathrm{~s}$, famous American cement concrete expert T.C.powers summarized many scholars work, puts forward the concrete early cold model: the macro model analysis of ice the frost heave phenomenon, this view is a theory with soil frost heave TABER - COLLINS, the introduction of concrete. [5] The basic is not a simple theories think that the cause of the frozen seas swell, and mainly comes from the moisture migration, make ice crystals increases, cause structural failure stress.

To give lectures in China in 1990, the international jian yan dong shi committee secretary general, the former Soviet union scholar up one of the fresh concrete cold immediately puts forward a new test results, which immediately cold $\mathrm{W} / \mathrm{C}=0.4$ migration than $\mathrm{W} / \mathrm{C}=0.7$, the analysis by the moisture migration is a major cause of immediate cold concrete structure damage.

In Heilongjiang province, Low temperature construction to the immediate suffering from ordinary concrete system research, think migration lead to freeze, lifelong damage to concrete structure. Ju-song zhang from Shenyang college of engineering in recognition outside migration is one of the frost injury and put forward the drying may also play a role of early frost damage, the moisture migration lead to two results: one is to increase the surface area of ice crystals, the crystallization pressure, destroyed the uniformity of concrete structure, has formed the structure of the damage action; The second is not generated inside the concrete is ice crystals, but the migration caused the concrete internal dry damage. For unsaturated a freezing and thawing frozen and dry the two factors on the effect of different stages of development of concrete is different. Immediately freezing cold concrete is migration caused uneven structure is given priority to, so when the concrete was still in the stage of plasticity, internal migration lead to drying shrinkage, not make the concrete structure damage. Instead advance keep cold damage in addition to the crystallization of the damage may be produced, dry damage is an important factor, because inside the concrete did not generate ice crystals, cold concrete in practical engineering is not a freeze. Have serious migration is icy cold concrete that is immediately, as to temperature, the development of the structure and suffered severe dry damage. So keep the shorter the time, the greater the final structure damage.[6]

This part of the narrative is mainly in view of the concrete in the early seas, to further distinguish the concrete process of the cold. Early concrete seas is refers to the concrete during maintenance and hardening of the seas, in the meantime of water is being grown up more concrete, so the moisture migration severe damage to the concrete structure. And migration caused by the dry seriously affected 
the normal concrete curing and strength increasing.

\section{SUMMARY}

To sum up, the main is a kind of mechanical behavior of concrete from damaging, namely the movement of water on the influence of the concrete structure. Concrete can be frozen water expands when it freezes in and produce the hydrostatic pressure, osmotic pressure, moisture migration, structural failure. Some relative factors also mentioned at the same time, the form of the concrete water, full of water, dry degree, etc. Through the further understanding of the mechanism for the concrete frost resistance, believe we can find out more perfect plan to improve the antifreeze performance of concrete.

\section{References}

[1]Feng $\mathrm{Xu}$, Some known on the problem of frost resistance of concrete, Concrete and cement products, 5 (1989) : 14.

[2]Shiyuan Huang, concrete material foundation of Winter construction, Concrete and reinforced concrete, 5 (1989) :57.

[3]Tianyuan Li, Try to talk about frost damage mechanism of concrete, Concrete and cement products, 5 (1989) : 8.

[4]Jianhua Jin, Xin Liao,1986. the new method Frost evaluate to resistance of concrete, Concrete and cement products, 5 (1986):7.

[5]Dinghua xu,Concrete material lecture about 6. Concrete antifreeze theory, Tianjin university Publishing Inc, Tianjin, 1986. pp. 9.

[6]Jusong Zhang, Keep cold damage mechanism of concrete early, Concrete, 4 (1998) :45. 